\title{
Concerns About Information Regarding COVID-19 on the Internet: Cross-Sectional Study
}

Yusui Zhao, MSc; Shuiyang Xu, BA; Lei Wang, MSc; Yu Huang, MSc; Yue Xu, MSc; Yan Xu, MSc; Qiaohong Lv, MSc; Zhen Wang ${ }^{*}$, MSc; Qingqing Wu ${ }^{*}$, MSc

Zhejiang Provincial Center for Disease Control and Prevention, Hangzhou, China

* these authors contributed equally

\section{Corresponding Author:}

Qingqing $\mathrm{Wu}, \mathrm{MSc}$

Zhejiang Provincial Center for Disease Control and Prevention

3399 Binsheng Road

Hangzhou, 310051

China

Phone: 8657187115239

Email: qqwu@cdc.zj.cn

\begin{abstract}
Background: Since the outbreak of COVID-19, the Chinese government and the Chinese Center for Disease Control and Prevention have released COVID-19-related information to the public through various channels to raise their concern level of the pandemic, increase their knowledge of disease prevention, and ensure the uptake of proper preventive practices.

Objective: Our objectives were to determine Chinese netizens' concerns related to COVID-19 and the relationship between their concerns and information on the internet. We also aimed to elucidate the association between individuals' levels of concern, knowledge, and behaviors related to COVID-19.

Methods: The questionnaire, which consisted of 15 closed-ended questions, was designed to investigate Chinese netizens' knowledge about COVID-19. The self-selection online survey method of nonprobability sampling was used to recruit participants through Dingxiangyisheng WeChat (a public, medical, and health service platform in China) accounts. Standard descriptive statistics and multivariate logistic regression analyses were conducted to analyze the data.

Results: In total, 10,304 respondents were surveyed on the internet (response rate $=1.75 \% ; 10,304 / 590,000)$. Nearly all ( $\mathrm{n}=9803$, 95.30\%) participants were concerned about "confirmed cases" of COVID-19, and $87.70 \%(\mathrm{n}=9036)$ received information about the outbreak through social media websites. There were significant differences in participants' concerns by sex $(P=.02)$, age $(P<.001)$, educational attainment $(P=.001)$, and occupation $(P<.001)$. All knowledge questions and preventive practices were associated with concerns about COVID-19. The results of the multivariate logistic regression indicated that participants' sex, educational attainment, occupation and employment status, knowledge acquisition, and concern level were significantly associated with the practice of proper preventive behaviors.

Conclusions: This study elucidated Chinese netizens' concerns, information sources, and preventive behaviors related to the COVID-19 pandemic. Sex, educational attainment, occupation and employment status, knowledge acquisition, and level of concern were key factors associated with proper preventive behaviors. This offers a theoretical basis for the government to provide targeted disease prevention and control information to the public.
\end{abstract}

(J Med Internet Res 2020;22(11):e20487) doi: 10.2196/20487

\section{KEYWORDS}

coronavirus; COVID-19; disease prevention; internet; knowledge

\section{Introduction}

In December 2019, the first cases of COVID-19 were detected in Wuhan, Hubei Province, China. Soon after, the pandemic spread rapidly across China and abroad [1]. As a result of the rapidly increasing numbers of confirmed cases and deaths, the public paid unprecedented attention to the pandemic [2]. By February 1, 2020, 14,380 cases and 304 deaths had been confirmed in China [3]. 
Internet access has increased worldwide during the past decade, reaching $48 \%$ of the world population in 2017 [4]. As of December 31, 2018, there were 829 million internet users in China (a penetration rate of 59.6\%) [5]. Compared with severe acute respiratory syndrome (SARS) in 2003 [6], the Middle Eastern respiratory syndrome (MERS) [7], and the Zika virus [8], people are more willing to learn about the current pandemic and acquire relevant protection knowledge over the internet [9]. As there is currently neither a vaccine nor a specific drug treatment for COVID-19, performing personal protection behaviors is still the most effective measure to control the pandemic.

Local governments have responded with a series of interventions to raise public concerns [10], including raising the level of emergency response [11] and traffic restrictions [12]. Concurrently, disease prevention and control organizations have employed varied means of health education to encourage the public's preventive behaviors. For example, the Chinese Center for Disease Control and Prevention (China CDC) issued COVID-19 Guidelines for Public Protection (version 2). A printed edition was distributed in the community, and an downloadable electronic version was made available on the official website [13]. Further, the local mainstream media, websites, and a 24-hour telephone hotline disseminated information about behaviors to prevent respiratory communicable diseases. Previous research has found that the more the public pays attention to public health emergencies, the easier it will be for them to take the initiative to seek knowledge regarding disease-related prevention and control, adopt correct personal protective behaviors, and improve support for local disease-related prevention and control policies $[14,15]$. There is also a large number of scientific literature that reports on people's knowledge, attitudes, and behaviors related to infectious diseases $[6,8]$. However, to the best of our knowledge, there is limited research addressing the relationships between the public's level of concern and knowledge of and behaviors related to infectious disease prevention [16]. Based on the above theory, our hypothesis is that there may be a certain association between the public's concerns, knowledge, and preventive practices related to COVID-19. In addition, raising the level of public concern regarding the risks related to COVID-19 may be an important prerequisite in influencing the public's understanding, and may be a key entry point in enhancing self-protection.

Hence, our main objectives were to determine Chinese netizens' concerns related to COVID-19 and its relationship with internet content, and to elucidate the association between individuals' concerns, knowledge, and preventive practices related to COVID-19.

\section{Methods}

\section{Design}

Following Facebook and Twitter's success in medical education in Western universities [17], WeChat is a new media app that is currently recognized as the best social networking site to use for a similar purpose, given that its users span all ages and professions in China [18]. There are currently an estimated 963 million WeChat users in China [5]. As a result, WeChat has been widely utilized in medical fields and has had a positive influence. Dingxiangyisheng WeChat is a public, medical, and health service platform in China. It mainly provides reliable online consultation services, health knowledge lectures, professional science articles, and other services for the domestic public. As the largest professional medical website in China, it has more than 5.5 million users and receives millions of daily visitors. Its users are mainly those who care about their health and that of their families, especially young Chinese mothers.

This study used opportunity sampling. A message with a questionnaire related to COVID-19 was sent to all users with a Dingxiangyisheng WeChat account. Individuals who were users of a WeChat account could participate in this study through their mobile phone or computer. In summary, 590,000 users read this information, and 10,304 of them volunteered to participate in this survey. To avoid repeated questionnaire submission, each respondent could only submit the questionnaire once per registered phone number. Questionnaires could not be revised or repeated after submission. This study was approved by the Ethics Committee of the Zhejiang Provincial CDC.

\section{Participants}

A cross-sectional, population-based internet survey was conducted from January 31 to February 2, 2020, at the beginning of the COVID-19 pandemic in China [19]. Participants were aged $\geq 15$ years and lived in China. Participation was voluntary without any financial incentive. Participants' personal information was kept confidential and stored at Dingxiangyisheng. Participants who did not fully complete the questionnaire were excluded.

\section{Questionnaire}

The online questionnaire, designed by health educational experts from the Zhejiang CDC, consisted of 15 closed-ended questions that aimed to collect the following information from respondents (Multimedia Appendix 1):

1. Sociodemographic and background information, including age, sex, province, occupation and employment status, educational attainment, and infection status (6 questions).

2. Concerns related to COVID-19 (1 question). A 3-point Likert-type scale was used to ascertain the level of concern (1=very, 2=general, and 3=not at all).

3. Participants' actual knowledge of COVID-19, including four aspects: its incubation period, transmission routes, symptoms, and knowledge of personal disease prevention behaviors (4 questions).

4. Practices of preventive measures against COVID-19, including mask wearing, handwashing with soap at home, avoiding public places and public transportation, and proper way to sneeze (4 questions).

Prior to administering the online survey, the questionnaire was pilot tested using the interception sampling method. Inspectors stopped passersby at a regular intersection and asked if they would be willing to answer the survey, which took approximately 10 minutes to complete. The survey questionnaire was pilot tested in January $2020(\mathrm{~N}=100)$ to ensure practicability and interpretability of answers. For our online survey 
$(\mathrm{N}=10,304)$, the overall Cronbach $\alpha$ value was 0.771 . The Kaiser-Meyer-Olkin test coefficient was 0.578. By factor analysis, the cumulative contribution rate of the four factors with a characteristic root greater than 1 was 44.866, indicating that the questionnaire has good reliability and validity.

\section{Data Analyses}

Data were analyzed using SPSS, version 13.0 (IBM Corp). Sociodemographic and background information was converted into classification variables or grade variables, and the corresponding composition ratio was calculated. For questions about knowledge and practices of preventive measures, answers of "yes" were coded into the correct knowledge and practices, while answers of "no" and "unclear" were coded into incorrect knowledge and practices. The nonparametric Mann-Whitney test was used for comparisons among groups with different characteristics, and the Kruskal-Wallis $\mathrm{H}$ test was used for comparisons among multiple groups. Questions regarding knowledge and personal protective measures were expressed by dichotomous variables. Mann-Whitney $U$ tests of two independent samples were conducted to identify apparent associations between individuals' concerns with knowledge and practices of preventive measures. A $P$ value $<.05$ was considered significant.

\section{Results}

\section{Participants' Characteristics}

A total of 10,304 individuals completed the online survey (response rate=1.75\%; 10,304/590,000). Participants' sociodemographic characteristics are shown in Table 1. 
Table 1. Participants' sociodemographic characteristics $(\mathrm{N}=10,304)$.

\begin{tabular}{|c|c|}
\hline Variable & Participants, n (\%) \\
\hline \multicolumn{2}{|l|}{ Sex } \\
\hline Male & $2670(25.91)$ \\
\hline Female & $7634(74.09)$ \\
\hline \multicolumn{2}{|l|}{ Age (years) } \\
\hline $15-20$ & $901(8.74)$ \\
\hline $21-30$ & $4830(46.88)$ \\
\hline $31-40$ & $2945(28.58)$ \\
\hline $41-50$ & $1141(11.07)$ \\
\hline $51-60$ & $403(3.91)$ \\
\hline$\geq 60$ & $84(0.82)$ \\
\hline \multicolumn{2}{|l|}{ Educational attainment } \\
\hline No education & $92(0.89)$ \\
\hline Primary & $434(4.21)$ \\
\hline Preparatory & $1117(10.84)$ \\
\hline Secondary & $7219(70.06)$ \\
\hline University graduate & $1442(13.99)$ \\
\hline \multicolumn{2}{|l|}{ Occupation and employment status } \\
\hline Government and public institution staff & $1729(16.78)$ \\
\hline Enterprise/commercial/service worker & $4100(39.79)$ \\
\hline Farmer & $104(1.01)$ \\
\hline Retired & $202(1.96)$ \\
\hline Homemaker & $751(7.29)$ \\
\hline Student & $1894(18.38)$ \\
\hline Unemployed & $395(3.83)$ \\
\hline Medical staff & $668(6.48)$ \\
\hline Other & $461(4.47)$ \\
\hline \multicolumn{2}{|l|}{ Infection status } \\
\hline Confirmed case & $0(0)$ \\
\hline Suspected case & $29(0.28)$ \\
\hline Close contact with a confirmed case & $293(2.84)$ \\
\hline None of the above & $9982(96.88)$ \\
\hline
\end{tabular}

\section{Participants' Concerns and Their Information Sources}

Table 2 presents data regarding participants' information sources and what they were concerned about. Nearly all participants were concerned about the number of confirmed cases. Most of the information about the outbreak was received through a social media website, while far less was obtained through traditional mass media (eg, television and newspapers). 
Table 2. Participants' concerns and information sources related to COVID-19.

\begin{tabular}{ll}
\hline Variable & Participants, $\mathrm{n}(\%)$ \\
\hline Concern & $9803(95.30)$ \\
$\quad$ Confirmed cases & $8463(82.27)$ \\
Number of deaths & $8131(79.04)$ \\
Number of recovered & $6942(67.48)$ \\
Suspected cases & $4795(46.61)$ \\
Number of severe patients & \\
Information source & $9036(87.70)$ \\
Social media website & $4556(44.22)$ \\
Smartphone app & $4054(39.35)$ \\
Television & $2447(23.75)$ \\
Friends/relatives & $2201(21.36)$ \\
Government website & $1111(10.78)$ \\
Short message service & $1070(10.39)$ \\
Community outreach & $679(6.59)$ \\
Newspaper & $166(1.61)$ \\
Significant other/partner & \\
\hline
\end{tabular}

\section{Concerns According to Participants' Characteristics}

Since the number of participants who reported they were "unconcerned" was very small, we merged the "unconcerned" and "general" categories, resulting in two categories for level of concern: "very" concerned or "general/unconcerned." Table 3 presents the concerns according to participants' characteristics. There were significant differences in concerns by sex, age, educational attainment, and occupation-specifically, women, those who were older, those who were more educated, and those who were retired expressed a greater level of concern than their counterparts. Students were least concerned compared to other occupation types. There were marginally significant differences between infection status and concerns; those with close contact with a confirmed case were more concerned about COVID-19 than the other types listed in Table 3. 
Table 3. Concerns about COVID-19 according to participants' characteristics.

\begin{tabular}{|c|c|c|c|c|}
\hline Variable & Very $(\mathrm{n}=8112), \mathrm{n}(\%)$ & General/not at all $(\mathrm{n}=2177), \mathrm{n}(\%)$ & $\mathrm{Z}$ or $\chi^{2}$ & $P$ value \\
\hline Sex & & & $\chi^{2}=2.42$ & .02 \\
\hline Male & $2146(80.37)$ & $524(19.63)$ & & \\
\hline Female & $5966(78.15)$ & $1668(21.85)$ & & \\
\hline Age (years) & & & $\mathrm{Z}=318.28$ & $<.001$ \\
\hline $15-20$ & $610(67.70)$ & $291(32.30)$ & & \\
\hline $21-30$ & $3542(73.33)$ & $1288(26.67)$ & & \\
\hline $31-40$ & $2517(85.47)$ & $428(14.53)$ & & \\
\hline $41-50$ & $1004(87.99)$ & $137(12.01)$ & & \\
\hline $51-60$ & $364(90.32)$ & $39(9.68)$ & & \\
\hline$\geq 60$ & 75 (89.29) & $9(9.71)$ & & \\
\hline Educational attainment & & & $\mathrm{Z}=11.97$ & .001 \\
\hline No education & $70(76.09)$ & $20(21.91)$ & & \\
\hline Primary & $340(78.34)$ & $93(21.66)$ & & \\
\hline Preparatory & $846(75.74)$ & $270(24.26)$ & & \\
\hline Secondary & $5678(78.65)$ & $1530(21.34)$ & & \\
\hline University graduate & $1178(81.69)$ & $264(18.31)$ & & \\
\hline Occupation and employment status & & & $Z=35.50$ & $<.001$ \\
\hline Government and public institution staff & $1461(84.50)$ & $268(15.50)$ & & \\
\hline Enterprise/commercial/service worker & $3234(78.88)$ & $866(21.12)$ & & \\
\hline Farmer & $85(81.73)$ & $19(18.27)$ & & \\
\hline Retired & $181(89.60)$ & $21(10.40)$ & & \\
\hline Homemaker & $613(81.62)$ & $138(18.38)$ & & \\
\hline Student & $1300(68.64)$ & $594(31.36)$ & & \\
\hline Unemployed & $286(72.41)$ & $109(27.59)$ & & \\
\hline Medical staff & $572(85.63)$ & $96(14.37)$ & & \\
\hline Other & $380(82.43)$ & $81(17.57)$ & & \\
\hline Infection status & & & $\mathrm{Z}=5.83$ & .054 \\
\hline Suspected case & $18(62.07)$ & $11(37.93)$ & & \\
\hline Close contact & $234(79.86)$ & $59(20.14)$ & & \\
\hline None of the above & $7860(78.74)$ & $2122(21.26)$ & & \\
\hline
\end{tabular}

\section{Concerns About COVID-19 According to Related} Knowledge and Preventive Practices

For all knowledge questions, participants who were more (vs less) concerned about COVID-19 were significantly more likely to master relevant knowledge. For almost all practice-related questions, participants who had more (vs less) concerns about COVID-19 were significantly more likely to take the right action to avoid SARS-CoV-2 infection. Notably, less concerned participants were more likely to avoid public places and public transportation than other participants (Table 4). 
Table 4. Concerns about COVID-19 according to related knowledge and preventive practices.

\begin{tabular}{|c|c|c|c|c|c|}
\hline Variable & Very, n $(\%)$ & General/not at all, n (\%) & Total, n (\%) & $\chi^{2}$ & $P$ value \\
\hline \multicolumn{6}{|l|}{ Knowledge items (proportion answered correctly) } \\
\hline Incubation period & $7041(86.80)$ & $1829(83.51)$ & $8870(86.08)$ & 16.24 & $<.001$ \\
\hline Transmission routes & $6212(76.58)$ & $1619(74.05)$ & $7831(76.00)$ & 6.99 & .009 \\
\hline Symptoms & $6675(82.29)$ & $1663(76.21)$ & $8338(80.92)$ & 46.05 & $<.001$ \\
\hline Personal preventive knowledge & $7020(86.54)$ & $1826(83.37)$ & $8846(85.85)$ & 14.87 & $<.001$ \\
\hline \multicolumn{6}{|l|}{ Preventive practices } \\
\hline Knows how to wear a mask when going out & $7916(97.58)$ & $2111(96.42)$ & $10,027(97.31)$ & 10.79 & $<.001$ \\
\hline Washes hands after getting home & $7548(93.05)$ & $1878(85.90)$ & $9426(91.48)$ & 120.32 & $<.001$ \\
\hline $\begin{array}{l}\text { Avoids going to public places and using public } \\
\text { transportation }\end{array}$ & $2160(26.63)$ & $519(23.61)$ & $2679(26.00)$ & 7.81 & .005 \\
\hline Can cough or sneeze properly & $4822(59.44)$ & $1142(52.18)$ & $5964(57.88)$ & 38.18 & $<.001$ \\
\hline
\end{tabular}

\section{Multivariate Logistic Regression}

For the analysis, respondents who answered the 4 knowledge questions correctly were deemed to have mastered COVID-19 preventive knowledge; otherwise, they were deemed to have not mastered it. Similarly, respondents who correctly answered the 4 questions related to preventive practices were regarded as having correct preventive practices, while those who did not were regarded as not having correct preventive practices. Preventive practices were used as the dependent variable, while sex, age, educational attainment, occupational status, and knowledge acquisition were used as independent variables in the multivariate regression analysis. The multivariate logistic regression revealed the factors that contributed to having correct preventive practices (Table 5). Women were more likely than men $(P=.001)$ to practice the correct precautions. Participants with more education (secondary, $P=.03$; university graduate, $P=.01$ ) were more likely to perform the right preventive practices than those with less educational attainment. Students were less likely to take the right preventive practices compared to other occupational groups $(P=.02)$. Concern $(P<.001)$ and knowledge acquisition $(P=.001)$ regarding the COVID-19 outbreak were significantly associated with proper preventive practices.

Table 5. Multivariate logistic regression of factors that contributed to performing preventive practices.

\begin{tabular}{|c|c|c|c|c|c|c|}
\hline Variables & $\mathrm{B}$ & SE & Wald $\chi^{2}$ & $P$ value & Odds ratio & $95 \% \mathrm{CI}$ \\
\hline \multicolumn{7}{|l|}{ Sex (reference: male) } \\
\hline Female & -0.22 & 0.07 & 10.84 & .001 & 0.80 & $0.70-0.91$ \\
\hline \multicolumn{7}{|c|}{ Educational attainment (reference: no education) } \\
\hline Secondary & -0.26 & 0.12 & 4.71 & .03 & 0.77 & $0.61-0.98$ \\
\hline University graduate & -0.20 & 0.08 & 6.01 & .01 & 0.82 & $0.70-0.96$ \\
\hline \multicolumn{7}{|c|}{ Occupation and employment status (reference: government and public institution staff) } \\
\hline Student & 0.38 & 0.17 & 5.19 & .02 & 1.46 & $1.05-2.02$ \\
\hline \multicolumn{7}{|c|}{ Knowledge acquisition (reference: no) } \\
\hline Yes & -0.19 & 0.06 & 10.98 & .001 & 0.83 & $0.74-0.93$ \\
\hline \multicolumn{7}{|c|}{ Concern (reference: very) } \\
\hline General/not at all & 0.48 & 0.08 & 38.16 & $<.001$ & 1.61 & $1.39-1.88$ \\
\hline
\end{tabular}

\section{Discussion}

\section{Principal Findings}

This study elucidated the concerns and information sources related to the COVID-19 pandemic of Chinese netizens. We also determined the relationship between these individuals' concerns and their personal protection knowledge and behaviors.

Our results revealed that the vast majority of the sample were very concerned about this outbreak. Among all surveyed participants, $78.73 \%$ were "very concerned," which is significantly higher than that found in a study involving Chinese residents during the SARS pandemic [20]. On the one hand, as the pandemic developed rapidly in early February, the Chinese government and relevant departments took a variety of strict prevention and control measures, including disseminating information through various media platforms [10,12]. On the other hand, with the continuous popularization of the internet in China, the public has more opportunities to obtain information 
that directly concerns them than ever before, which motivates them to actively take preventive measures [21].

The number of confirmed COVID-19 cases per day was the item that nearly all participants were concerned about. In response, China's National Health Commission and health departments at all levels announce the number of confirmed cases in cities and counties daily through official media websites to keep the public informed of new outbreaks in the region. With the rapid development of the internet worldwide, the way the public obtains health information has changed greatly since the SARS [6], H7N9 [22], and Zika [23] outbreaks. Specifically, the proportion of traditional media, such as television and newspapers, has gradually decreased, while the proportion of new media, such as websites and smartphone apps, has gradually increased [24]. This suggests that, when there is a new infectious disease outbreak, the government should release information to the public through an official website and other relevant media to increase public awareness as soon as possible, and ensure that the correct information is disseminated to foster protective knowledge and behavior.

Consistent with previous studies [25], we found that most people have the right knowledge to prevent COVID-19, especially those who were "very" concerned about the pandemic. Surprisingly, we found that the percentage of respondents electing to avoid going to public places and using public transportation was "very low" compared to other personal preventive practices. It is worth noting that the outbreak happened during the Spring Festival holiday in China; thus, population mobility had increased. Even in the face of such a severe outbreak, most people did not avoid going to public places or using public transportation [12].

As in previous studies [24,26], we found a statistically significant association between sex and personal preventive practices. Women are more likely than men to take the right preventive practices. Although a univariate analysis found significant statistical differences between age and personal preventive practices, multivariate logistic regression analysis did not find such differences. This disparity in the results might be explained by the collinearity between age and educational attainment when we conducted the multivariate logistic regression analysis. Students were significantly less concerned about the outbreak than other occupational groups. Moreover, students were less likely to take proper preventive practices than other occupational groups. Students who were less interested in acquiring information about diseases and utilizing protective measures would increase their risk of infection [8]. Thus, before returning to school, students should be educated about the transmission of COVID-19 and how to develop good personal hygiene habits.

Increased attention to the pandemic was associated with increased knowledge about prevention and control, which coincides with previous results [27]. This shows that knowledge acquisition and the adoption of appropriate behaviors are closely related to individuals' disease-related concerns. For individuals who are not concerned, stakeholders need to increase health education and ensure they receive the appropriate information.

\section{Strengths and Limitations}

The strength of our study is its large sample, which was recruited during a critical period - the early stages of the COVID-19 outbreak. Similar to the results of a recent online survey about COVID-19 [28], our sample was overrepresentative of women, well-educated people, and white-collar workers.

There are several limitations to this study. First, owing to limited access to the internet and online health information resources, certain populations such as the elderly and rural residents were insufficiently represented; therefore, this study is not representative of all Chinese people. The study, which recruited participants through Dingxiangyisheng WeChat, had a bias in favor of women, especially young Chinese mothers. Second, we employed a cross-sectional design; therefore, we only revealed correlations between variables and cannot infer causal links between them. More in-depth scientific research is needed.

\section{Conclusions}

This study elucidated the concerns, information sources, and preventive behaviors of Chinese netizens related to the COVID-19 pandemic. Sex, educational attainment, occupation and employment status, knowledge acquisition, and concern level were key factors associated with proper preventive behaviors. This offers a theoretical basis for the government to provide targeted disease prevention and control information disseminated to the public.

\section{Acknowledgments}

We thank the Ethics Committee of the Zhejiang Provincial CDC for their approval. We appreciate the staff of Dingxiangyisheng for facilitating data collection. We also thank the editor and anonymous reviewers for their constructive comments on improving this manuscript.

\section{Conflicts of Interest}

None declared.

\section{Multimedia Appendix 1}

COVID-19 prevention and treatment questionnaire in Chinese.

[DOC File, 355 KB-Multimedia Appendix 1]

\section{References}


1. Zhu N, Zhang D, Wang W, Li X, Yang B, Song J, et al. A Novel Coronavirus from Patients with Pneumonia in China, 2019. N Engl J Med 2020 Feb 20;382(8):727-733. [doi: 10.1056/nejmoa2001017]

2. Chen S, Yang J, Yang W, Wang C, Bärnighausen T. COVID-19 control in China during mass population movements at New Year. The Lancet 2020 Mar;395(10226):764-766. [doi: 10.1016/s0140-6736(20)30421-9]

3. Update on pneumonia outbreak by novel coronavirus as of 24 o'clock on February 1, 2020. National Health Commission, People's Republic of China. 2020 Feb 2. URL: http://www.nhc.gov.cn/xcs/yqtb/202002/d5c495da742f4739b7f99339c3bd032f. shtml [accessed 2020-02-02]

4. The state of broadband 2017: broadband catalyzing sustainable development. International Telecommunications Union/UNESCO. 2017 Sep. URL: https://www.itu.int/dms pub/itu-s/opb/pol/s-pol-broadband.18-2017-pdf-e.pdf [accessed 2020-03-26]

5. The 43rd statistical report on Internet development in China. China Internet Network Information Center. 2019 Feb. URL: http://www.cac.gov.cn/wxb pdf/0228043.pdf [accessed 2019-07-17]

6. Vartti AM, Oenema A, Schreck M, Uutela A, de Zwart O, Brug J, et al. SARS knowledge, perceptions, and behaviors: a comparison between Finns and the Dutch during the SARS outbreak in 2003. Int J Behav Med 2009;16(1):41-48 [FREE Full text] [doi: 10.1007/s12529-008-9004-6] [Medline: 19184625$]$

7. Alsahafi A, Cheng A. Knowledge, Attitudes and Behaviours of Healthcare Workers in the Kingdom of Saudi Arabia to MERS Coronavirus and Other Emerging Infectious Diseases. Int J Environ Res Public Health 2016 Dec 06;13(12):1214 [FREE Full text] [doi: 10.3390/ijerph13121214] [Medline: 27929452]

8. Plaster AN, Painter JE, Tjersland DH, Jacobsen KH. University Students' Knowledge, Attitudes, and Sources of Information About Zika Virus. J Community Health 2018 Aug 9;43(4):647-655. [doi: 10.1007/s10900-017-0463-z] [Medline: 29318503]

9. Fan KS, Ghani SA, Machairas N, Lenti L, Fan KH, Richardson D, et al. COVID-19 prevention and treatment information on the internet: a systematic analysis and quality assessment. BMJ Open 2020 Sep 10;10(9):e040487 [FREE Full text] [doi: 10.1136/bmjopen-2020-040487] [Medline: 32912996]

10. Tian H, Liu Y, Li Y, Wu C, Chen B, Kraemer MUG, et al. An investigation of transmission control measures during the first 50 days of the COVID-19 epidemic in China. Science 2020 May 08;368(6491):638-642. [doi: 10.1126/science.abb6105] [Medline: 32234804$]$

11. Tibet activates highest-level public health alert. Chinadaily. 2020 Jan 29. URL: http://www.chinadaily.com.cn/a/202001/ 29/WS5e318a36a3101282172739c1.html [accessed 2020-01-30]

12. Kraemer MUG, Yang C, Gutierrez B, Wu C, Klein B, Pigott DM, Open COVID-19 Data Working Group, et al. The effect of human mobility and control measures on the COVID-19 epidemic in China. Science 2020 May 01;368(6490):493-497 [FREE Full text] [doi: 10.1126/science.abb4218] [Medline: 32213647]

13. COVID-19 Guidelines for Public Protection (version 2). Chinese Center For Disease Prevention. 2020. URL: http://www. chinacdc.cn/jkzt/crb/zl/szkb 11803/jszl 11815/202003/P020200306330231617651.pdf [accessed 2020-03-06]

14. Suri G, Gross JJ. The role of attention in motivated behavior. J Exp Psychol Gen 2015 Aug; 144(4):864-872. [doi: 10.1037/xge0000088] [Medline: 26097978]

15. Tamers SL, Allen J, Yang M, Stoddard A, Harley A, Sorensen G. Does concern motivate behavior change? Exploring the relationship between physical activity and body mass index among low-income housing residents. Health Educ Behav 2014 Dec 30;41(6):642-650 [FREE Full text] [doi: 10.1177/1090198114532289] [Medline: 24786794]

16. Kennedy CJ, Probart CK, Dorman SM. The relationship between radon knowledge, concern and behavior, and health values, health locus of control and preventive health behaviors. Health Educ Q 1991 Sep 04;18(3):319-329. [doi: 10.1177/109019819101800305] [Medline: 1917508 ]

17. Forgie SE, Duff JP, Ross S. Twelve tips for using Twitter as a learning tool in medical education. Medical Teacher 2012 Dec 21;35(1):8-14. [doi: 10.3109/0142159x.2012.746448]

18. Fujimori M, Morais TC, França E, Toledo ORD, Honório-França A. The attitudes of primary school children to breastfeeding and the effect of health education lectures. J Pediatr (Rio J) 2008 May 30;84(3):224-231. [doi: 10.2223/jped.1791]

19. Zhao Y, Cheng S, Yu X, Xu H. Chinese Public's Attention to the COVID-19 Epidemic on Social Media: Observational Descriptive Study. J Med Internet Res 2020 May 04;22(5):e18825 [FREE Full text] [doi: 10.2196/18825] [Medline: 32314976]

20. Mingyi Q, Dongmei Y, Wei D, Zheng H, Lili Z, Xinghua L. Behaviour, Cognition and Emotion of the Public in Beijing towards SARS. Chin Ment Health J 2003;17:515-520 [FREE Full text]

21. Kim Y, Zhong W, Jehn M, Walsh L. Public risk perceptions and preventive behaviors during the 2009 H1N1 influenza pandemic. Disaster Med Public Health Prep 2015 Apr 17;9(2):145-154. [doi: 10.1017/dmp.2014.87] [Medline: 25882121]

22. Ma X, Liao Q, Yuan J, Liu Y, Liu Y, Chen J, et al. Knowledge, attitudes and practices relating to influenza A(H7N9) risk among live poultry traders in Guangzhou City, China. BMC Infect Dis 2014 Oct 18;14(1):554 [FREE Full text] [doi: 10.1186/s12879-014-0554-8] [Medline: 25324011]

23. Casapulla SL, Aidoo-Frimpong G, Basta T, Grijalva M. Zika virus knowledge and attitudes in Ecuador. AIMS Public Health 2018;5(1):49-63 [FREE Full text] [doi: 10.3934/publichealth.2018.1.49] [Medline: $\underline{30083569]}$ 
24. Wang P, Lu W, Ko N, Chen Y, Li D, Chang Y, et al. COVID-19-Related Information Sources and the Relationship With Confidence in People Coping with COVID-19: Facebook Survey Study in Taiwan. J Med Internet Res 2020 Jun 05;22(6):e20021 [FREE Full text] [doi: 10.2196/20021] [Medline: 32490839]

25. Clements JM. Knowledge and Behaviors Toward COVID-19 Among US Residents During the Early Days of the Pandemic: Cross-Sectional Online Questionnaire. JMIR Public Health Surveill 2020 May 08;6(2):e19161 [FREE Full text] [doi: 10.2196/19161] [Medline: $\underline{32369759}$ ]

26. Li S, Feng B, Liao W, Pan W. Internet Use, Risk Awareness, and Demographic Characteristics Associated With Engagement in Preventive Behaviors and Testing: Cross-Sectional Survey on COVID-19 in the United States. J Med Internet Res 2020 Jun 16;22(6):e19782 [FREE Full text] [doi: 10.2196/19782] [Medline: 32501801]

27. Cui B, Liu ZP. Factors Associated with Knowledge and Personal Protective Behavior Related to Avian Influenza A (H7N9) Risk among Chinese Poultry Farmers. Popul Health Manag 2016 Aug;19(4):298-299. [doi: 10.1089/pop.2015.0182] [Medline: 27007253]

28. Zhong B, Luo W, Li H, Zhang Q, Liu X, Li W, et al. Knowledge, attitudes, and practices towards COVID-19 among Chinese residents during the rapid rise period of the COVID-19 outbreak: a quick online cross-sectional survey. Int J Biol Sci 2020;16(10):1745-1752 [FREE Full text] [doi: 10.7150/ijbs.45221] [Medline: 32226294]

\title{
Abbreviations \\ China CDC: Chinese Center for Disease Control and Prevention \\ MERS: Middle Eastern respiratory syndrome \\ SARS: severe acute respiratory syndrome
}

\author{
Edited by G Eysenbach, R Kukafka; submitted 20.05.20; peer-reviewed by C Mavrot, N Khalili-Mahani, S Zhang; comments to author \\ 29.06.20; revised version received 16.07.20; accepted 19.10.20; published 09.11.20 \\ Please cite as: \\ Zhao Y, Xu S, Wang L, Huang Y, Xu Y, Xu Y, Lv Q, Wang Z, Wu $Q$ \\ Concerns About Information Regarding COVID-19 on the Internet: Cross-Sectional Study \\ J Med Internet Res 2020;22(11):e20487 \\ URL: http://www.jmir.org/2020/11/e20487/ \\ doi: $10.2196 / 20487$ \\ PMID: 33095740
}

(CYusui Zhao, Shuiyang Xu, Lei Wang, Yu Huang, Yue Xu, Yan Xu, Qiaohong Lv, Zhen Wang, Qingqing Wu. Originally published in the Journal of Medical Internet Research (http://www.jmir.org), 09.11.2020. This is an open-access article distributed under the terms of the Creative Commons Attribution License (https://creativecommons.org/licenses/by/4.0/), which permits unrestricted use, distribution, and reproduction in any medium, provided the original work, first published in the Journal of Medical Internet Research, is properly cited. The complete bibliographic information, a link to the original publication on http://www.jmir.org/, as well as this copyright and license information must be included. 